Neuromuscular electrical stimulation prevents muscle wasting in critically ill, comatose patients.

Peer-reviewed author version

Dirks, Marlou; HANSEN, Dominique; Van Assche, Aimé; DENDALE, Paul \& van Loon, Luc (2014) Neuromuscular electrical stimulation prevents muscle wasting in critically ill, comatose patients.. In: CLINICAL SCIENCE, 128 (6), 357-365.

DOI: $10.1042 / C S 20140447$

Handle: http://hdl.handle.net/1942/17617 


\section{Neuromuscular electrical stimulation prevents muscle wasting in critically ill, comatose patients}

${ }^{1}$ Marlou L. Dirks, MSc; ${ }^{2}$ Dominique Hansen, PhD; ${ }^{2}$ Aimé Van Assche, MD; ${ }^{2}$ Paul Dendale, MD, $\mathrm{PhD}$; and ${ }^{1}$ Luc J.C. van Loon, PhD

${ }^{1}$ NUTRIM School for Nutrition, Toxicology and Metabolism, Maastricht University, Maastricht, the Netherlands

${ }^{2}$ Jessa Hospital, Heart Centre Hasselt, Hasselt, and Rehabilitation Research Center (REVAL), Hasselt University, Faculty of Medicine, Diepenbeek, Belgium

Address for correspondence:

Prof. L.J.C. van Loon, PhD

NUTRIM School for Nutrition, Toxicology and Metabolism

Maastricht University Medical Centre

P.O. Box 616

$6200 \mathrm{MD}$, Maastricht, the Netherlands

Phone: +3143 3881397

Fax: +31 433670976

Email: L.vanLoon@maastrichtuniversity.nl

Running title: NMES prevents muscle atrophy during critical illness

Keywords: NMES, critical illness, muscle wasting, ICU, skeletal muscle, disuse atrophy

Clinical trial registration: NCT01521637

Word count: 3407

No funding was obtained for this study 


\begin{abstract}
1 Abstract
2

3 Fully-sedated patients, being treated in the ICU, experience substantial skeletal muscle loss. 4 Consequently, survival rate is reduced and full recovery after awakening is compromised. 5 Neuromuscular electrical stimulation (NMES) represents an effective method to stimulate 6 muscle protein synthesis and alleviate muscle disuse atrophy in healthy subjects. We investigated 7 the efficacy of twice-daily NMES to alleviate muscle loss in six fully-sedated ICU patients 8 admitted for acute critical illness ( $n=3$ males, $n=3$ females; age $63 \pm 6 \mathrm{y}$; APACHE II disease 9 severity-score: $29 \pm 2$ ). One leg was subjected to twice-daily NMES of the quadriceps muscle for 10 a period of $7 \pm 1 \mathrm{~d}$ while the other leg acted as non-stimulated control (CON). Directly before the 11 first and on the morning after the final NMES session, quadriceps muscle biopsies were collected 12 from both legs to assess muscle fiber-type specific cross-sectional area (CSA). Furthermore, 13 phosphorylation status of key proteins involved in the regulation of muscle protein synthesis was 14 assessed, and mRNA expression of selected genes was measured. In the CON leg, type I and 15 type II muscle fiber CSA decreased by $16 \pm 9$ and $24 \pm 7 \%$, respectively $(P<0.05)$. No muscle 16 atrophy was observed in the stimulated leg. NMES increased mTOR phosphorylation by $19 \%$ 17 when compared to baseline $(\mathrm{P}<0.05)$, with no changes in the $\mathrm{CON}$ leg. Furthermore, mRNA 18 expression of key genes involved in muscle protein breakdown either declined (FOXO1; $\mathrm{P}<0.05)$ 19 or remained unchanged (MAFBx and MuRF1), with no differences between legs. In conclusion, 20 NMES represents an effective and feasible interventional strategy to prevent skeletal muscle 21 atrophy in critically ill, comatose patients.
\end{abstract}

Abstract word count: 249

24 


\section{Introduction}

Critically ill patients suffer from extensive muscle wasting, which occurs rapidly at the onset of an ICU stay [1-3]. Aside from an increased risk of mortality [4, 5], consequences to this muscle loss include muscle weakness, prolonged mechanical ventilation, fatigue, decreases in muscle strength, impaired glucose homeostasis and delayed recovery and rehabilitation [6-9]. ENREF 5 Muscle atrophy in ICU patients exceeds that seen in normal hospitalized or bedridden persons $[10,11]$. Moreover, ICU patients who are mechanically ventilated and deeply sedated are thought to be even more susceptible to muscle wasting and subsequent negative health consequences due to a complete lack of muscle contraction. Despite this, no data are currently available concerning muscle fiber atrophy in this specific ICU patient subpopulation.

Early ambulation has been proven a successful rehabilitation strategy in non-sedated ICU patients in terms of improving functional outcomes and overall prognosis [12]. However, in fully-sedated patients, early ambulation is not feasible and, as such, alternative strategies should be defined to alleviate muscle wasting. Neuromuscular electrical stimulation (NMES) is an effective means to invoke involuntary muscle contractions. Previously, NMES has been shown to attenuate the loss of muscle mass and strength experienced by non-sedated ICU patients [13] and healthy individuals subjected to limb immobilization [14]. However, the potential for NMES to rescue muscle mass in fully-sedated, comatose ICU patients has not been investigated. In the present study, we investigated our hypothesis that daily NMES attenuates skeletal muscle fiber atrophy in fully-sedated, comatose ICU patients. Fully-sedated ICU patients, expected to be sedated for a minimum of three days, were included in the present study. NMES was performed twice-daily on the quadriceps of one leg, whereas the other leg served as a sham-treated control. Prior to and immediately after the intervention, plasma samples were taken to assess any systemic changes in amino acid availability during the experiment, and muscle biopsies were taken from both legs to assess muscle fiber atrophy and myocellular characteristics. Additionally, RT-PCR and Western blotting were performed on collected muscle tissue samples to assess the potential impact of NMES on basal mRNA and protein expression levels of key genes involved in the regulation of muscle mass maintenance. 
Methods

\section{Patients}

All patients admitted to the Intensive Care Unit (ICU) of Jessa Hospital, Hasselt, Belgium between March 2012 and July 2013 were assessed for eligibility for the present study (see eFigure1). Patients admitted to the ICU were screened by the nursing staff, and were excluded if one or more of the following exclusion criteria were met: $<18$ or $>80 \mathrm{y}$ old, not expected to undergo complete sedation, suffering from spinal cord injury, recent arterial surgery on the legs, local wounds that prohibit the application of neuromuscular electrical stimulation (NMES), chronic use of corticosteroids, intake of certain antithrombotic drugs, or the presence of an implantable cardioverter-defibrillator (ICD) and/or pacemaker. Secondly, the expected sedation time was estimated by the responsible physician and patients were excluded if this was $<3$ days. All patients who were excluded based on an expected short sedation time were re-evaluated after $24 \mathrm{~h}$, and included if the revised expected sedation time was $>3 \mathrm{~d}$. Participants were accepted into the study after written informed consent was obtained from their legal representatives. The study was approved by the Medical Ethical Committee of the Jessa Hospital in accordance with the Declaration of Helsinki.

\section{Study design}

An overview of the experimental protocol is depicted in eFigure 2. Patients were included in the study directly after informed consent was obtained from their legal representatives, which was generally given within $2.5 \mathrm{~d}$ after admission to the ICU (depicted in column 'Time to inclusion' in Table 1). After this, patient's legs were randomly assigned as either the control (CON) or stimulated (NMES) leg, counterbalanced for left and right legs. Randomization was performed by an independent investigator, and treatment allocation was performed by using sequentially labeled envelopes which were opened after inclusion of subjects. Baseline measurements were then taken, which consisted of assessment of leg circumference (measured at different locations on the upper leg), obtaining an arterial blood sample, and obtaining a muscle biopsy from both legs. After the pre-measurements, NMES was performed twice-daily on one leg (NMES) whereas the other leg served as a control $(\mathrm{CON})$. Post-measurements were performed on the final day of sedation, with a minimum study duration of 3 days and a maximum of 10 days. The study duration for each patient is depicted in Table 1. Post-measurements were performed prior to subjects being awake. Standard medical care was not altered, and passive mobilization was performed on both legs according to standard care procedures.

\section{Data collection}

At baseline, data on demographic and clinical characteristics of the patients were obtained, including information necessary to determine the severity of illness. These data were scored according to the Acute Physiology and Chronic Health Evaluation II (APACHE II) system with higher values indicating more severe illness and more therapeutic interventions, respectively [15].

Arterial blood samples were collected from the catheter already placed in the arteria radialis. Blood $(10 \mathrm{~mL})$ was collected into EDTA-containing tubes and immediately centrifuged at $1,000 \mathrm{~g}$ for $10 \mathrm{~min}$ at $4^{\circ} \mathrm{C}$. Aliquots of plasma were directly snap-frozen in liquid nitrogen and stored at $-80^{\circ} \mathrm{C}$ until further analysis. Processing and storage of the samples was done by

99 UBiLim (Universitaire Biobank Limburg, Hasselt, Belgium). Plasma amino acid concentrations 
were measured using ultra-performance liquid chromatography tandem mass spectrometry as described previously [16], and results are displayed in eTable2.

In addition, during the pre- and post-measurements, a muscle biopsy sample was collected from each leg. After injection of local anesthesia, percutaneous needle biopsy samples were collected from $m$. vastus lateralis, approximately $15 \mathrm{~cm}$ above the patella using the Bergström technique [17].

\section{Neuromuscular electrical stimulation}

Neuromuscular electrical stimulation sessions were performed both in the morning (11:00 AM) and afternoon (4.30 PM). Four self-adhesive electrodes ( $2 \mathrm{~mm}$ thick, 50 x $50 \mathrm{~mm}$ ) were placed on the distal part at the muscle belly of the $m$. rectus femoris and the $m$. vastus lateralis, and at the inguinal area of both muscles. The electrodes were connected to an Enraf-Nonius TensMed S84 stimulation device (Enraf-Nonius, Rotterdam, the Netherlands), discharging biphasic symmetric rectangular-wave pulses. The position of the electrodes was re-marked daily with a semi-permanent marker to maintain the same location of stimulation for each session. The NMES protocol was composed of a warm-up phase $(5 \mathrm{~min}, 5 \mathrm{~Hz}, 250 \mu \mathrm{s})$, a stimulation period $(30 \mathrm{~min}, 100 \mathrm{~Hz}, 400 \mu \mathrm{s}, 5 \mathrm{~s}$ on $(0.75 \mathrm{~s}$ rise, $3.5 \mathrm{~s}$ contraction, $0.75 \mathrm{~s}$ fall) and $10 \mathrm{~s}$ off), and a cooling-down phase $(5 \mathrm{~min}, 5 \mathrm{~Hz}, 250 \mu \mathrm{s})$. The intensity of the stimulation was set to a level at which full contractions of $m$. quadriceps femoris were both visible and palpable. The intensity was raised approximately every 3 min when a full muscle contraction was no longer achieved with the current intensity. This protocol was based on our previous work showing increased rates of muscle protein synthesis after a single bout of NMES [18], and applied on the immobilized leg of healthy young adults [14]. During the NMES sessions, four electrodes and compatible cables were also applied to the control leg to standardize all procedures (representing a sham treatment).

\section{Dietary intake}

When patients were hemodynamically stable, enteral feeding was started according to routine guidelines of the ICU at Jessa Hospital as early as possible. Patients were fed Nutrison Multi Fibre (containing $420 \mathrm{~kJ}, 16 \mathrm{en} \%$ protein, 49 en $\%$ carbohydrates, and 35 en $\%$ fat per $100 \mathrm{~mL}$ ). Generally, patients were fed maximally $80 \mathrm{~mL}$ per hour with short intervals during which nutritional supply was paused. Gastric emptying was determined by the nursing staff, and food administration was altered accordingly. Nutritional support was not modulated and was applied according to the standard medical care in this ICU.

\section{Muscle analyses}

Muscle samples were freed from any visible non-muscle tissue and separated into different sections; the first part ( $30 \mathrm{mg}$ ) was imbedded in Tissue-Tek (Sakura Finetek, Zoeterwoude, the Netherlands), frozen on liquid nitrogen cooled isopentane and used to determine muscle fibertype specific cross-sectional area (CSA) and satellite cell content as done previously.[19] The second part $(\sim 15 \mathrm{mg})$ was snap frozen in liquid nitrogen and used for real time-PCR analysis to determine mRNA expression of selected genes as described before,[14, 20] and compared ENREF 19 with mRNA expression of $n=6$ healthy, age- and gender-matched controls. The third part $(\sim 40 \mathrm{mg})$ was snap frozen in liquid nitrogen for Western Blot analysis to determine the total content and phosphorylation status of several key proteins of interest as described previously [18]. All muscle analyses were performed by an investigator blinded to 
treatment. A detailed overview of the muscle analyses is presented in the supplemental 147 information.

\section{Statistics}

150 Based on data from previous studies in healthy subjects in our laboratory [14, 21], we calculated 151 that 8 patients would be required to detect a $8 \%$ difference in muscle fiber CSA between CON 152 and NMES over 7 days (using an $\alpha$ level of 0.05 and a $\beta$ level of 0.10 ). All data presented are 153 expressed as means \pm SEM. Baseline differences between legs were compared with a paired 154 samples t-test. Pre- and post-intervention data were analyzed using repeated measures analysis of 155 variance (ANOVA) with time (pre vs post) and treatment (CON vs NMES) as factors. Fiber type 156 (type I vs type II) was added as a third within-subjects factor when analyzing all muscle fiber 157 characteristics. In case of significant interaction (time $x$ treatment), paired-samples t-tests were 158 performed to determine time effects within the CON and NMES leg separately. Alternatively, when a time $x$ treatment effect was observed for muscle fiber characteristics, a 2-way ANOVA was performed for the CON and NMES leg separately, with time and treatment as factors. For the mRNA analyses, differences between patients and healthy controls were tested by means of an independent samples t-test between the mean value of the CON and NMES leg in patients and the values observed in healthy controls. Statistical analyses were performed using the SPSS version 20.0 software package (SPSS Inc., Chicago, IL, USA), with $P<0.05$ as the value for 165 statistical significance. 


\section{Results}

\section{Patients}

Between March 2012 and July 2013, 9 patients were included in the present study. Two patients awoke after $<3$ study days and one patient died. Therefore, the presented results represent data collected from 6 patients. Clinical characteristics of the included patients are listed in Table 1. Energy intake per day averaged $5.31 \pm 0.56 \mathrm{MJ}$, with a mean protein intake of $0.56 \pm 0.06 \mathrm{~g} \cdot \mathrm{kg}$ body weight ${ }^{-1} \cdot$ day $^{-1}$.

\section{Neuromuscular electrical stimulation}

Within 5 min of the start of the actual 30 min stimulation period, a full muscle contraction was achieved. The intensity of the NMES intervention for subjects averaged $29.9 \mathrm{~mA}$ during the first session and was progressively increased to $32.3 \mathrm{~mA}$ in the final session.

\section{Muscle fiber characteristics}

Figure 1 illustrates the delta change in muscle fiber cross-sectional area (CSA) in both the NMES and CON legs throughout the study. Table 2 details skeletal muscle fiber type specific characteristics at baseline and following $7 \pm 1 \mathrm{~d}$ of full sedation in both legs. In the CON leg, a significant decline of $16 \pm 9 \%$ and $24 \pm 7 \%$ was observed in type I and II muscle fiber CSA, respectively (time effect; $P<0.05$ ). In contrast, the NMES leg showed no atrophy in either type I or II muscle fibers (time $x$ treatment interaction effect; $P<0.05$ ). Muscle fiber type distribution showed an overall significant time $x$ treatment interaction effect (see Table $2 ; P<0.05$ ), with a shift from type I towards type II fibers in the CON leg, and a shift towards more type I fibers in the NMES leg. At baseline, satellite cell content was greater in type I vs type II muscle fibers (expressed per muscle fiber, per millimeter squared, and as a percentage of total myonuclei). No differences in muscle fiber type specific myonuclear content, myonuclear domain size or satellite cell content were observed between legs or over time.

\section{$m R N A$ expression}

Figure 2 displays the relative muscle mRNA expression of key genes involved in the regulation of muscle protein synthesis and breakdown in the CON and NMES leg before and after the intervention, as well as for a group of healthy, age- and gender-matched controls. At baseline, mRNA expression did not differ between NMES and CON legs. However, MAFBx, MuRF1, FOXO1, mTOR and P70S6K were all more highly expressed in the patients compared with healthy controls $(P<0.01)$. There was a significant time effect $(P<0.05)$ such that FOXO1 and P70S6K expression decreased during the period of sedation, with no differences between legs. Expression levels for all other genes did not reveal any interaction or time effects. The mRNA expression of additional genes involved in the regulation of myogenesis, oxidative metabolism, mechano-sensing and cellular amino acid transport are presented in eFigure 3 (supplemental material).

\section{Signaling proteins}

The skeletal muscle content and phosphorylation status of key proteins involved in the regulation of muscle protein synthesis are displayed in Figure 3. Neither total protein content, nor phosphorylation status of Akt was affected by time or the intervention (both $P>0.05$ ). Whereas muscle mTOR content was unaffected by time or treatment, a significant time $x$ treatment 
213 interaction effect $(P<0.05)$ was found for the phosphorylation status of mTOR. mTOR

214 phosphorylation increased by as much as $19 \pm 5 \%$ in the NMES leg $(P<0.05)$, with no changes in 215 the CON leg $(P>0.05)$. Muscle P70S6K total protein content decreased following the 216 intervention in both legs (time effect, $P<0.05$ ), without changes in phosphorylation status $217(P>0.05)$. 


\section{Discussion}

In the present study, we demonstrate for the first time that fully-sedated patients experience substantial type I and type II muscle fiber atrophy during a $\sim 7 \mathrm{~d}$ stay in the ICU. Daily application of neuromuscular electrical stimulation (NMES) effectively prevents skeletal muscle fiber atrophy, offering an effective and feasible interventional strategy to alleviate muscle wasting in comatose ICU patients.

General admission to the ICU has been shown to cause substantial muscle wasting [22] with a decline in type I and type II muscle fiber cross-sectional area of 3\% and $4 \%$ per day, respectively [2]. In keeping with this, we show a $2.8 \%$ and $4.4 \%$ decline in muscle fiber size in type I and II muscle fibers, respectively, in fully-sedated patients (i.e. no possibility of voluntary muscle contraction) during on average 7 days in the ICU (Figure 1). By way of comparison, muscle atrophy brought about by disuse only in healthy humans (i.e. limb immobilization) leads to a $0.5 \%$ and $0.9 \%$ per day decline in type I and II muscle fiber cross-sectional area (CSA), respectively [21]. This implies that the mechanisms responsible for muscle wasting in the ICU are not simply attributed to disuse. One possible contributing factor could be inadequate nutritional status. Sufficient dietary protein is considered a key factor in the maintenance of muscle mass [23-25], and previous research has shown that sufficient protein intake is associated with reduced mortality rates in critically ill patients $[26,27]$. In the current study, patients received $0.56 \pm 0.06 \mathrm{~g}$ protein $\cdot \mathrm{kg}$ body weight ${ }^{-1} \cdot$ day $^{-1}$, which is below the current guidelines of 1.3-2.0 g protein $\cdot \mathrm{kg}$ body weight ${ }^{-1} \cdot$ day $^{-1}$ recommended during critical illness [28, 29], and has likely contributed to the extensive level of muscle wasting. In support, plasma amino acid concentrations in our patients declined throughout the sedated state (eTable 2). In agreement, previous work has reported declines in circulating amino acid concentrations during critical illness [30]. Such a decline in circulating amino acid concentrations likely reduces amino acid uptake in muscle [31] and, as such, could modulate the efficacy of NMES as a means to stimulate muscle protein synthesis rates.

From a mechanistic viewpoint, disuse atrophy has been primarily attributed to declines in muscle protein synthesis rates [20, 32-34]. However, it has been suggested that in various conditions associated with rapid muscle wasting a multitude of other factors (e.g. increased inflammation, higher metabolic stress responses etc.) may stimulate muscle proteolysis, driving much of the muscle loss [35]. In line with this, we see evidence of the severely metabolically compromised condition of our patients as demonstrated by numerous clinical chemistry indictors obtained throughout the study (e.g. high white blood cell counts and C-reactive protein (CRP) concentrations; eTable 1). In keeping with this, molecular markers that have been used as a proxy for changes in muscle protein breakdown rate were elevated upon admission to the ICU, when compared with a group of healthy subjects (i.e. MAFBx, MuRF1 and FOXO1; Figure 2). The subsequent decline in the expression levels of these genes suggest a decline in muscle protein turnover during hospital stay but expression levels remained elevated when compared to healthy controls. This is not unexpected given the metabolic stress response upon ICU admission [36]. In contrast to previous work investigating the impact of NMES on an immobilized leg [14], we observed no significant differences in the expression levels of various genes between the stimulated and unstimulated leg in this comatose ICU setting. The absence of such differences may be attributed to various factors, but underline our understanding that changes in the expression and phosphorylation levels of various genes being used as a proxy for changes in muscle protein breakdown and synthesis do not necessarily represent changes in muscle protein breakdown and synthesis rates and do not necessarily translate to a net increase or decrease in 
muscle mass [37]. Taken together, the present data highlight the need for immediate and effective intervention at the onset of ICU admission to stimulate muscle protein synthesis and inhibit proteolysis, thereby preventing or attenuating extensive muscle wasting. An interesting observation in the stimulated leg was that NMES reversed the decline in phosphorylation status of mTOR (Figure 3D), which seems to be in line with previous work showing that NMES increases muscle protein synthesis rates [18].

Daily application of NMES has been shown to prevent muscle atrophy in healthy subjects during a week of leg immobilization [14]. Moreover, clinical trials have demonstrated beneficial effects of NMES on muscle function in various bed-rested populations, including patients suffering from COPD [38, 39] and sepsis [40, 41]. The current study demonstrates, for the first time, that NMES is capable of preventing muscle wasting in fully-sedated patients during 7 days in the ICU (with a $+7 \pm 12 \%$ change in mixed muscle fiber CSA in the stimulated leg compared with a $21 \pm 8 \%$ decline in mixed muscle fiber CSA in the control leg; Figure 1). The prevention of muscle atrophy in these individuals can have profound clinical implications. For instance, maintaining muscle mass during critical illness has been shown to reduce mortality rates [4, 5]. Additionally, since muscle mass is vital for functional capacity [42], metabolic homeostasis [9], and immune function [43], maintaining muscle mass during an ICU stay is essential to allow proper recovery during rehabilitation. As such, preventing muscle wasting is imperative for promoting quality of life after hospital discharge and reducing the likelihood of rehospitalization. NMES in fully-sedated patients can be easily applied by nursing staff, is relatively cheap and does not seem to cause any adverse effects on vital parameters during or after the sessions [44]. Some difficulties applying NMES in ICU patients have been reported previously and are likely due to increased skin/soft tissue impedance and/or edema [13]. Despite experiencing similar problems in the present study, all NMES sessions could be successfully performed without any adverse effects. Taken together, our data demonstrate that NMES is practical and feasible as a countermeasure for muscle wasting in clinically compromised ICU patients. Future studies should address whether these findings would translate into longer-term benefits such as increased survival rates, reduced hospitalization length of stay and/or improved rehabilitation outcomes.

\section{Conclusion}

NMES represents an effective and feasible interventional strategy to prevent skeletal muscle wasting in critically ill, comatose patients. NMES may be applied effectively to offset negative consequences of muscle wasting and, as such, may increase survival and improve subsequent rehabilitation in these patients.

\section{Clinical Perspectives}

Fully-sedated patients experience substantial skeletal muscle loss that reduces survival rate and compromises full recovery. We investigated the efficacy of twice-daily neuromuscular electrical stimulation (NMES) to attenuate skeletal muscle loss in fully-sedated ICU patients admitted for acute critical illness. The non-stimulated leg showed substantial type I and type II muscle fiber atrophy (a $16 \pm 9$ and $24 \pm 7 \%$ decline in muscle fiber cross sectional area, respectively; $P<0.05$ ). In contrast, no atrophy was observed in the muscle fibers collected from the stimulated leg. Both mRNA and protein expression of key proteins involved in muscle protein metabolism were assessed to understand the molecular mechanisms involved. In conclusion, NMES represents an 
310 effective and feasible interventional strategy to prevent skeletal muscle atrophy in critically ill, 311 comatose patients. 


\section{Author contributions}

M.L. Dirks had full access to all of the data in the study and takes responsibility for the integrity of the data and the accuracy of the data. None of the authors disclose any conflicts of interest.

Study concept and design: M.L. Dirks, D. Hansen, A.van Assche, P. Dendale, and L.J.C. van Loon. Acquisition of data: M.L. Dirks and D. Hansen. Analysis and interpretation of the data: M.L. Dirks, D. Hansen, P. Dendale and L.J.C. van Loon. Drafting of the manuscript: M.L. Dirks. Critical revision of the manuscript for important intellectual content: D. Hansen, A. van Assche, P. Dendale and L.J.C. van Loon. Study supervision: A. van Assche, P. Dendale and L.J.C. van Loon.

\section{Additional contributions}

We gratefully acknowledge the enthusiasm and assistance of the physicians and nursing staff of the ICU in Jessa Hospital, with special thanks to Dr. P. Vranckx for his practical assistance. We would also like to thank Marika Leenders and Lex B. Verdijk for their practical support and Benjamin T. Wall for his assistance in drafting the manuscript. Furthermore, we are thankful for the assistance of dr. E. Bijnens, Department of Radiology at Jessa Hospital, and for the support and assistance provided by Biobank UbiLim at Jessa Hospital for processing and storage of the samples. 


\section{References}

1. Monk, D.N., Plank, L.D., Franch-Arcas, G., Finn, P.J., Streat, S.J., and Hill, G.L. (1996) Sequential changes in the metabolic response in critically injured patients during the first 25 days after blunt trauma. Ann Surg 223, 395-405

2. Helliwell, T.R., Wilkinson, A., Griffiths, R.D., McClelland, P., Palmer, T.E., and Bone, J.M. (1998) Muscle fibre atrophy in critically ill patients is associated with the loss of myosin filaments and the presence of lysosomal enzymes and ubiquitin. Neuropathol Appl Neurobiol 24, 507-17

3. Latronico, N. and Bolton, C.F. (2011) Critical illness polyneuropathy and myopathy: a major cause of muscle weakness and paralysis. Lancet Neurol 10, 931-41

4. Weijs, P.J., Looijaard, W.G., Dekker, I.M., Stapel, S.N., Girbes, A.R., Oudemans-van Straaten, H.M., and Beishuizen, A. (2014) Low skeletal muscle area is a risk factor for mortality in mechanically ventilated critically ill patients. Crit Care 18, R12

5. Moisey, L.L., Mourtzakis, M., Cotton, B.A., Premji, T., Heyland, D.K., Wade, C.E., Bulger, E., Kozar, R.A., for the, N., and Rehabilitation Investigators, C. (2013) Skeletal muscle predicts ventilator-free days, ICU-free days, and mortality in elderly ICU patients. Crit Care 17, R206

6. Levine, S., Nguyen, T., Taylor, N., Friscia, M.E., Budak, M.T., Rothenberg, P., Zhu, J., Sachdeva, R., Sonnad, S., Kaiser, L.R., Rubinstein, N.A., Powers, S.K., and Shrager, J.B. (2008) Rapid disuse atrophy of diaphragm fibers in mechanically ventilated humans. N Engl J Med 358, 1327-35

7. Herridge, M.S. (2009) Legacy of intensive care unit-acquired weakness. Crit Care Med 37, S457-61

8. Truong, A.D., Fan, E., Brower, R.G., and Needham, D.M. (2009) Bench-to-bedside review: mobilizing patients in the intensive care unit--from pathophysiology to clinical trials. Crit Care 13, 216

9. Nair, K.S. (2005) Aging muscle. Am J Clin Nutr 81, 953-63

10. Puthucheary, Z.A., Rawal, J., McPhail, M., Connolly, B., Ratnayake, G., Chan, P., Hopkinson, N.S., Padhke, R., Dew, T., Sidhu, P.S., Velloso, C., Seymour, J., Agley, C.C., Selby, A., Limb, M., Edwards, L.M., Smith, K., Rowlerson, A., Rennie, M.J., Moxham, J., Harridge, S.D., Hart, N., and Montgomery, H.E. (2013) Acute skeletal muscle wasting in critical illness. JAMA 310, 1591-600

11. Wall, B.T. and van Loon, L.J. (2013) Nutritional strategies to attenuate muscle disuse atrophy. Nutr Rev 71, 195-208

12. Schweickert, W.D., Pohlman, M.C., Pohlman, A.S., Nigos, C., Pawlik, A.J., Esbrook, C.L., Spears, L., Miller, M., Franczyk, M., Deprizio, D., Schmidt, G.A., Bowman, A., Barr, R., McCallister, K.E., Hall, J.B., and Kress, J.P. (2009) Early physical and occupational therapy in mechanically ventilated, critically ill patients: a randomised controlled trial. Lancet 373, 1874-82

13. Rodriguez, P.O., Setten, M., Maskin, L.P., Bonelli, I., Vidomlansky, S.R., Attie, S., Frosiani, S.L., Kozima, S., and Valentini, R. (2012) Muscle weakness in septic patients requiring mechanical ventilation: protective effect of transcutaneous neuromuscular electrical stimulation. J Crit Care 27, 319 e1-8 
14. Dirks, M.L., Wall, B.T., Snijders, T., Ottenbros, C.L., Verdijk, L.B., and van Loon, L.J. (2014) Neuromuscular electrical stimulation prevents muscle disuse atrophy during leg immobilization in humans. Acta Physiol (Oxf) 210, 628-41

15. Knaus, W.A., Draper, E.A., Wagner, D.P., and Zimmerman, J.E. (1985) APACHE II: a severity of disease classification system. Crit Care Med 13, 818-29

16. Waterval, W.A., Scheijen, J.L., Ortmans-Ploemen, M.M., Habets-van der Poel, C.D., and Bierau, J. (2009) Quantitative UPLC-MS/MS analysis of underivatised amino acids in body fluids is a reliable tool for the diagnosis and follow-up of patients with inborn errors of metabolism. Clin Chim Acta 407, 36-42

17. Bergstrom, J. (1975) Percutaneous needle biopsy of skeletal muscle in physiological and clinical research. Scand J Clin Lab Invest 35, 609-16

18. Wall, B.T., Dirks, M.L., Verdijk, L.B., Snijders, T., Hansen, D., Vranckx, P., Burd, N.A., Dendale, P., and van Loon, L.J. (2012) Neuromuscular electrical stimulation increases muscle protein synthesis in elderly type 2 diabetic men. Am J Physiol Endocrinol Metab 303, E614-23

19. Leenders, M., Verdijk, L.B., van der Hoeven, L., van Kranenburg, J., Nilwik, R., and van Loon, L.J. (2013) Elderly men and women benefit equally from prolonged resistancetype exercise training. J Gerontol A Biol Sci Med Sci 68, 769-79

20. Wall, B.T., Snijders, T., Senden, J.M., Ottenbros, C.L., Gijsen, A.P., Verdijk, L.B., and van Loon, L.J. (2013) Disuse impairs the muscle protein synthetic response to protein ingestion in healthy men. J Clin Endocrinol Metab 98, 4872-81

21. Snijders, T., Wall, B.T., Dirks, M.L., Senden, J.M., Hartgens, F., Dolmans, J., Losen, M., Verdijk, L.B., and van Loon, L.J. (2014) Muscle disuse atrophy is not accompanied by changes in skeletal muscle satellite cell content. Clin Sci (Lond) 126, 557-66

22. Reid, C.L., Campbell, I.T., and Little, R.A. (2004) Muscle wasting and energy balance in critical illness. Clin Nutr 23, 273-80

23. Paddon-Jones, D., Sheffield-Moore, M., Zhang, X.J., Volpi, E., Wolf, S.E., Aarsland, A., Ferrando, A.A., and Wolfe, R.R. (2004) Amino acid ingestion improves muscle protein synthesis in the young and elderly. Am J Physiol Endocrinol Metab 286, E321-8

24. Rennie, M.J., Edwards, R.H., Halliday, D., Matthews, D.E., Wolman, S.L., and Millward, D.J. (1982) Muscle protein synthesis measured by stable isotope techniques in man: the effects of feeding and fasting. Clin Sci 63, 519-23

25. Volpi, E., Mittendorfer, B., Wolf, S.E., and Wolfe, R.R. (1999) Oral amino acids stimulate muscle protein anabolism in the elderly despite higher first-pass splanchnic extraction. The American journal of physiology 277, E513-20

26. Strack van Schijndel, R.J., Weijs, P.J., Koopmans, R.H., Sauerwein, H.P., Beishuizen, A., and Girbes, A.R. (2009) Optimal nutrition during the period of mechanical ventilation decreases mortality in critically ill, long-term acute female patients: a prospective observational cohort study. Crit Care 13, R132

27. Weijs, P.J., Stapel, S.N., de Groot, S.D., Driessen, R.H., de Jong, E., Girbes, A.R., Strack van Schijndel, R.J., and Beishuizen, A. (2012) Optimal protein and energy nutrition decreases mortality in mechanically ventilated, critically ill patients: a prospective observational cohort study. JPEN J Parenter Enteral Nutr 36, 60-8

28. Martindale, R.G., McClave, S.A., Vanek, V.W., McCarthy, M., Roberts, P., Taylor, B., Ochoa, J.B., Napolitano, L., Cresci, G., American College of Critical Care, M., and Directors, A.S.P.E.N.B.o. (2009) Guidelines for the provision and assessment of nutrition 
support therapy in the adult critically ill patient: Society of Critical Care Medicine and American Society for Parenteral and Enteral Nutrition: Executive Summary. Crit Care Med 37, 1757-61

29. Singer, P., Berger, M.M., Van den Berghe, G., Biolo, G., Calder, P., Forbes, A., Griffiths, R., Kreyman, G., Leverve, X., Pichard, C., and Espen (2009) ESPEN Guidelines on Parenteral Nutrition: intensive care. Clin Nutr 28, 387-400

30. Jespersen, J.G., Nedergaard, A., Reitelseder, S., Mikkelsen, U.R., Dideriksen, K.J., Agergaard, J., Kreiner, F., Pott, F.C., Schjerling, P., and Kjaer, M. (2011) Activated protein synthesis and suppressed protein breakdown signaling in skeletal muscle of critically ill patients. PLoS One 6, e 18090

31. Pennings, B., Groen, B., de Lange, A., Gijsen, A.P., Zorenc, A.H., Senden, J.M., and van Loon, L.J. (2012) Amino acid absorption and subsequent muscle protein accretion following graded intakes of whey protein in elderly men. Am J Physiol Endocrinol Metab 302, E992-9

32. Biolo, G., Ciocchi, B., Lebenstedt, M., Barazzoni, R., Zanetti, M., Platen, P., Heer, M., and Guarnieri, G. (2004) Short-term bed rest impairs amino acid-induced protein anabolism in humans. J Physiol 558, 381-8

33. Biolo, G., Ciocchi, B., Lebenstedt, M., Heer, M., and Guarnieri, G. (2002) Sensitivity of whole body protein synthesis to amino acid administration during short-term bed rest. J Gravit Physiol 9, P197-8

34. Glover, E.I., Phillips, S.M., Oates, B.R., Tang, J.E., Tarnopolsky, M.A., Selby, A., Smith, K., and Rennie, M.J. (2008) Immobilization induces anabolic resistance in human myofibrillar protein synthesis with low and high dose amino acid infusion. The Journal of physiology 586, 6049-61

35. Egerman, M.A. and Glass, D.J. (2014) Signaling pathways controlling skeletal muscle mass. Crit Rev Biochem Mol Biol 49, 59-68

36. Constantin, D., McCullough, J., Mahajan, R.P., and Greenhaff, P.L. (2011) Novel events in the molecular regulation of muscle mass in critically ill patients. J Physiol 589, 388395

37. Greenhaff, P.L., Karagounis, L.G., Peirce, N., Simpson, E.J., Hazell, M., Layfield, R., Wackerhage, H., Smith, K., Atherton, P., Selby, A., and Rennie, M.J. (2008)

Disassociation between the effects of amino acids and insulin on signaling, ubiquitin ligases, and protein turnover in human muscle. Am J Physiol Endocrinol Metab 295, E595-604

38. Abdellaoui, A., Prefaut, C., Gouzi, F., Couillard, A., Coisy-Quivy, M., Hugon, G., Molinari, N., Lafontaine, T., Jonquet, O., Laoudj-Chenivesse, D., and Hayot, M. (2011) Skeletal muscle effects of electrostimulation after COPD exacerbation: a pilot study. Eur Respir J 38, 781-8

39. Zanotti, E., Felicetti, G., Maini, M., and Fracchia, C. (2003) Peripheral muscle strength training in bed-bound patients with COPD receiving mechanical ventilation: effect of electrical stimulation. Chest 124, 292-6

40. Poulsen, J.B., Moller, K., Jensen, C.V., Weisdorf, S., Kehlet, H., and Perner, A. (2011) Effect of transcutaneous electrical muscle stimulation on muscle volume in patients with septic shock. Crit Care Med 39, 456-61

41. Rodriguez, P.O., Setten, M., Maskin, L.P., Bonelli, I., Vidomlansky, S.R., Attie, S., Frosiani, S.L., Kozima, S., and Valentini, R. (2011) Muscle weakness in septic patients 
requiring mechanical ventilation: Protective effect of transcutaneous neuromuscular electrical stimulation. Journal of critical care

42. Maughan, R.J., Watson, J.S., and Weir, J. (1983) Strength and cross-sectional area of human skeletal muscle. J Physiol 338, 37-49

43. Nielsen, S. and Pedersen, B.K. (2008) Skeletal muscle as an immunogenic organ. Curr Opin Pharmacol 8, 346-51

44. Meesen, R.L.J., Dendale, P., Cuypers, K., Berger, J., Hermans, A., Thijs, H., and Levin, O. (2010) Neuromuscular Electrical Stimulation as a Possible Means to Prevent Muscle Tissue Wasting in Artificially Ventilated and Sedated Patients in the Intensive Care Unit: A Pilot Study. Neuromodulation 13, 315-321 


\section{Figure legends}

Figure 1: Changes in muscle fiber cross sectional area (CSA) in the control (CON) and stimulated (NMES) leg of sedated patients, after $7 \pm 1$ days of twice-daily NMES. A significant interaction effect $(P<0.05)$ was observed, and a time effect in the CON leg $(P<0.05)$. * Significantly ehange different from zero $(P<0.05)$.

Figure 2: Skeletal muscle mRNA expression of genes of interest. Abbreviations: FOXO1, Forkhead box protein O1; MAFbx, Muscle Atrophy F-box; MuRF1, Muscle RING-finger protein-1; mTOR, mammalian target of rapamycin; P70S6K, P70S6 kinase. * Significantly different from patients at baseline $(P<0.05)$. \# Significantly different from pre-value $(P<0.05)$.

Figure 3: Skeletal muscle protein expression of Akt, mTOR and P70S6K in the control (CON) and stimulated (NMES) leg, before (white bars) and after (black bars) $7 \pm 1$ days of twice-daily NMES. Left graphs: total protein expression, right graphs: phosphorylated/total expression. Abbreviations: mTOR, mammalian target of rapamycin; P70S6K, P70S6 kinase. * Significantly different from pre-intervention values $(P<0.05)$. 
Figure 1:

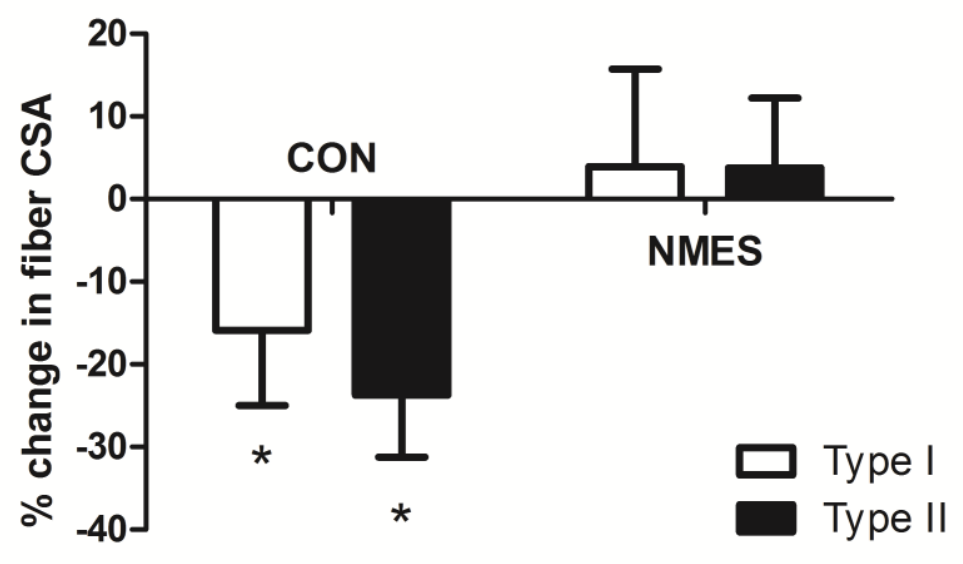

Figure 2:
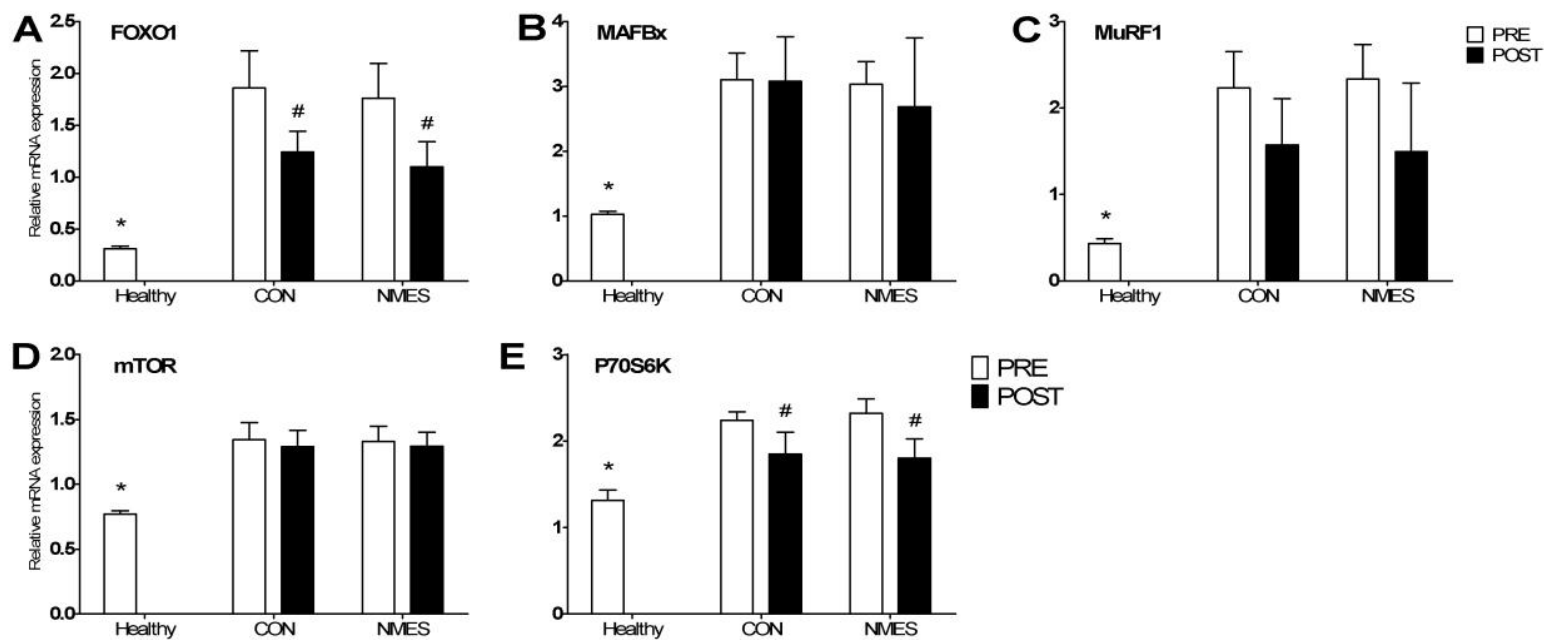
Figure 3:
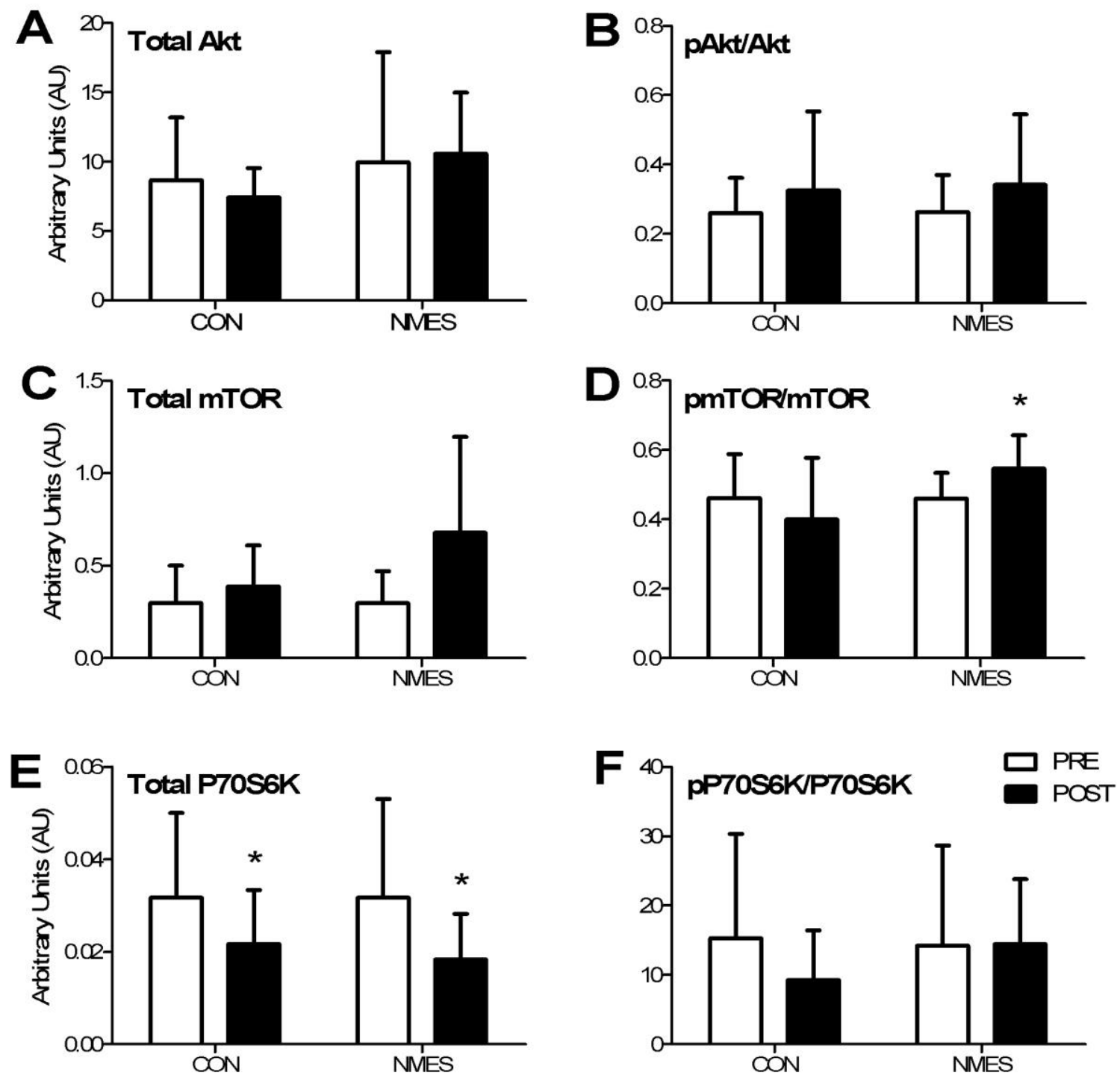
Table 1: Patients with critical illness. Fully-sedated patients were subjected to one-legged NMES for a period of 3-10 days, while the other leg served as non-stimulated control. Pre-intervention muscle measurements were performed immediately after obtaining informed content. Postintervention measurements were performed prior to awakening after a minimum of 3 and a maximum of 10 days.

\begin{tabular}{|c|c|c|c|c|c|c|c|}
\hline Diagnosis & Age & Sex & $\begin{array}{l}\text { APACHE II } \\
\text { at admission } \\
\end{array}$ & $\begin{array}{r}\text { Time to } \\
\text { inclusion (d) } \\
\end{array}$ & $\begin{array}{l}\text { Days in } \\
\text { study }\end{array}$ & Survival & Medication \\
\hline Urgent CABG & 78 & $\mathrm{M}$ & 32 & $\underline{3.5}$ & 3.5 & $\mathrm{D}$ & $\begin{array}{l}\text { Acetylcysteine, acetylsalicylic acid, alprazolam, } \\
\text { amiodarone, amoxicillin, bisoprolol, ciprofloxacine, } \\
\text { furosemide, haloperidol, hydrocortisone, insulin, } \\
\text { ipratropium bromide/ fenoterol hydrobromide, } \\
\text { isosorbide mononitrate, midazolam, milrinone, } \\
\text { molsidomine, morphine, nadroparin, norepinephrine } \\
\text { pantoprazole, piracetam, ramipril, spironolacton }\end{array}$ \\
\hline Pneumonia & 74 & M & 26 & $\underline{2.5}$ & 7.5 & $\mathrm{~S}$ & $\begin{array}{l}\text { Acetylsalicylic acid, ceftazidime, ciproflocacine, } \\
\text { erythromycin, methylprednisolone, nadroparin, } \\
\text { pantoprazole, ranitidine }\end{array}$ \\
\hline Herpetic encephalitis & 39 & $\mathrm{M}$ & 25 & $\underline{1}$ & 9 & $\mathrm{D}$ & $\begin{array}{l}\text { Acetylcysteine, acyclovir, amoxicillin, diazepam, } \\
\text { furosemide, HES, levetiracetam, midazolam, } \\
\text { nadroparin, norepinephrine, paracetamol, phenytoin, } \\
\text { propofol, thiopental, valproate }\end{array}$ \\
\hline Cerebral hemorrhage & 46 & $\mathrm{~F}$ & 29 & $\underline{1}$ & 7.5 & $S$ & $\begin{array}{l}\text { Aacidexam, acetylcysteine, bumetanide, ciprofloxacine, } \\
\text { clindamycin, fluconazole, furosemide, insulin, } \\
\text { ipratropium bromide/ fenoterol hydrobromide, lactulose, } \\
\text { meropenem, methylprednisolone, nadroparin, } \\
\text { norepinephrine, nystatin, pantoprazole, paracetamol, } \\
\text { piritramide, propofol, spironolacton, valproate }\end{array}$ \\
\hline Cerebral hemorrhage & 78 & $\mathrm{~F}$ & 29 & $\underline{4.5}$ & 7.5 & $\mathrm{D}$ & $\begin{array}{l}\text { Aacidexam, acetylcysteine, amoxicillin, ciprofloxacine, } \\
\text { dobutamine hydrochloride, furosemide, insulin, }\end{array}$ \\
\hline
\end{tabular}




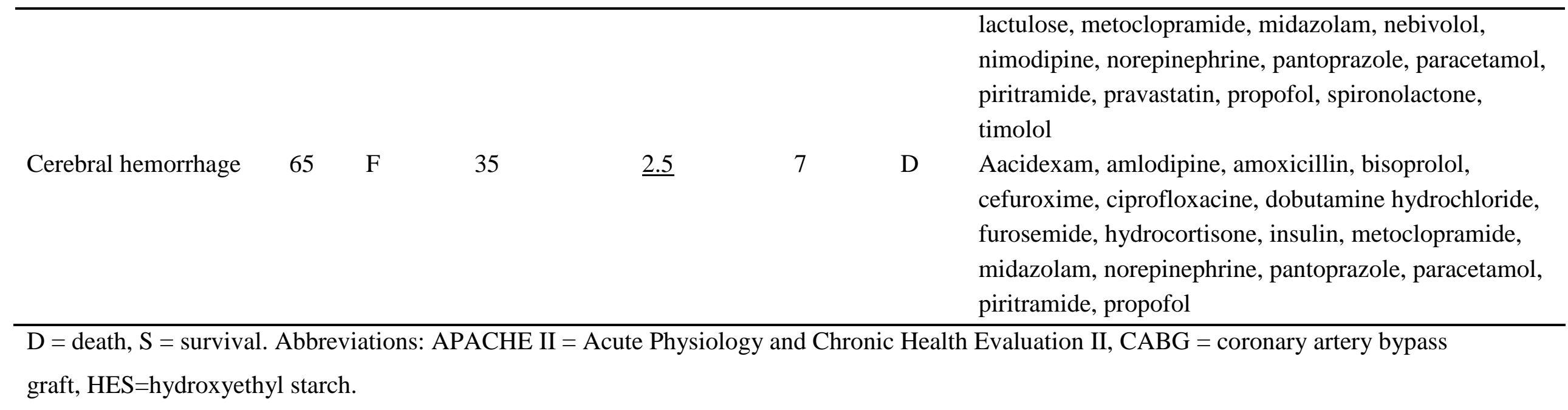


Table 2: Muscle fiber characteristics

\begin{tabular}{lccccc}
\hline & & \multicolumn{2}{c}{ CON } & \multicolumn{2}{c}{ NMES } \\
\hline Muscle fiber CSA $\left(\boldsymbol{\mu m}^{2}\right)$ & Fiber type & Pre & Post & Pre & Post \\
& I & $4560 \pm 261$ & $3879 \pm 484 *$ & $4414 \pm 441$ & $4512 \pm 550$ \\
\% Fiber & II & $3412 \pm 530$ & $2647 \pm 512 *$ & $3168 \pm 607$ & $3246 \pm 590$ \\
\% Fiber area & I & $53 \pm 8 \dagger$ & $45 \pm 5 \dagger$ & $42 \pm 6 \dagger$ & $46 \pm 6 \dagger$ \\
& II & $47 \pm 8 \dagger$ & $55 \pm 5 \dagger$ & $58 \pm 6 \dagger$ & $54 \pm 6 \dagger$ \\
Nuclei per fiber & I & $59 \pm 9$ & $56 \pm 8$ & $51 \pm 8$ & $55 \pm 7$ \\
Myonuclear domain $\left(\boldsymbol{\mu m ^ { 2 }}\right)$ & II & $41 \pm 9$ & $44 \pm 8$ & $49 \pm 8$ & $45 \pm 7$ \\
Number of SCs per fiber & I & $2.4 \pm 0.1$ & $2.5 \pm 0.2$ & $2.3 \pm 0.2$ & $2.6 \pm 0.2$ \\
& II & $2.1 \pm 0.2 \#$ & $2.1 \pm 0.2 \#$ & $1.9 \pm 0.2 \#$ & $2.3 \pm 0.3 \#$ \\
Number of SCs per $\mathbf{~ m m}^{2}$ & I & $1853 \pm 69$ & $1574 \pm 183$ & $1931 \pm 110$ & $1760 \pm 142$ \\
& I & $1573 \pm 162 \#$ & $1255 \pm 203 \#$ & $1618 \pm 153 \#$ & $1452 \pm 220 \#$ \\
SCs/myonuclei $(\%)$ & II & $0.061 \pm 0.015 \#$ & $0.049 \pm 0.013 \#$ & $0.048 \pm 0.008 \#$ & $0.055 \pm 0.009 \#$ \\
& I & $18.8 \pm 2.9$ & $22.7 \pm 2.7$ & $17.6 \pm 1.7$ & $22.1 \pm 4.1$
\end{tabular}


Data represent means \pm SEM. Abbreviations: SC, satellite cell; SCs/myonuclei (\%), the number of SCs as a percentage of the total number of myonuclei (i.e. number of myonuclei + number of SCs). * Significantly different from pre-intervention value $(P<0.05)$. \# Significantly different from type I fiber value $(P<0.05)$. $\uparrow$ Significant treatment*time* fiber type interaction effect $(P<0.05)$ 


\section{Supplemental material}

eMethods

eFigure 1: Patient flow

eFigure 2: Overview of the experimental protocol

Leg circumference measurements

Muscle analysis

eResults

eTable1: Average laboratory values during the study period

Plasma amino acid concentrations

eTable 2: Plasma AA concentrations

Leg circumference

mRNA analysis

eFigure 3: Skeletal muscle mRNA expression of genes of interest page 2

page 3

page 3

page 4

page 9

page 9

page 10

page 11

page 11

page 12 
eMethods

eFigure 1: Patient flow

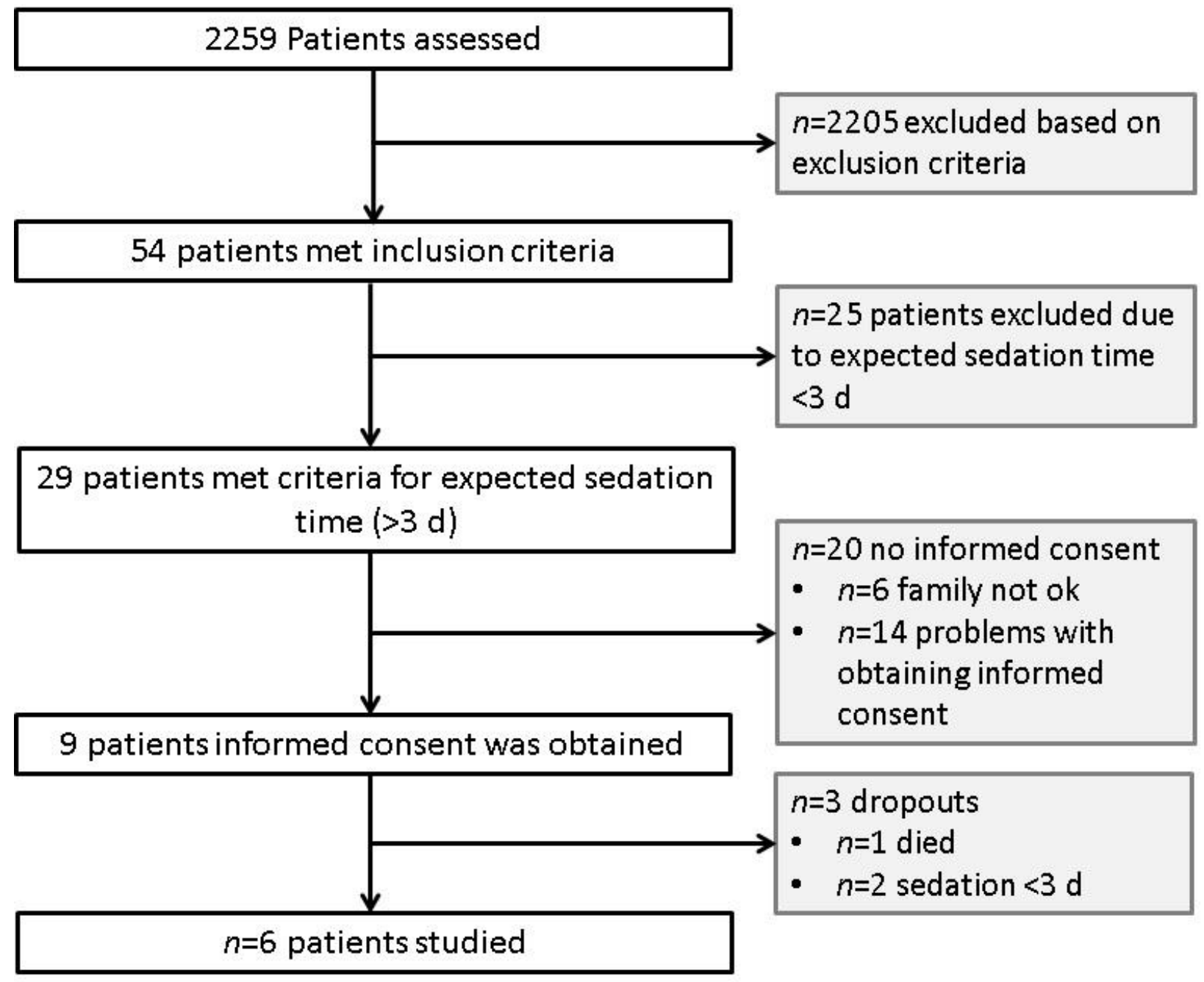


eFigure 2: Overview of the experimental protocol. Upper part: Overview of the study, in which fully-sedated patients were subjected to minimally 3 days and maximally 10 days of NMES. Post-intervention measurements were performed prior to patient awakening. Lower part: detailed overview of each study day. ' $\ldots$ '. represents the duration between ICU admission and obtaining informed consent from the patient's legal representatives (i.e. on average 2.5 days).

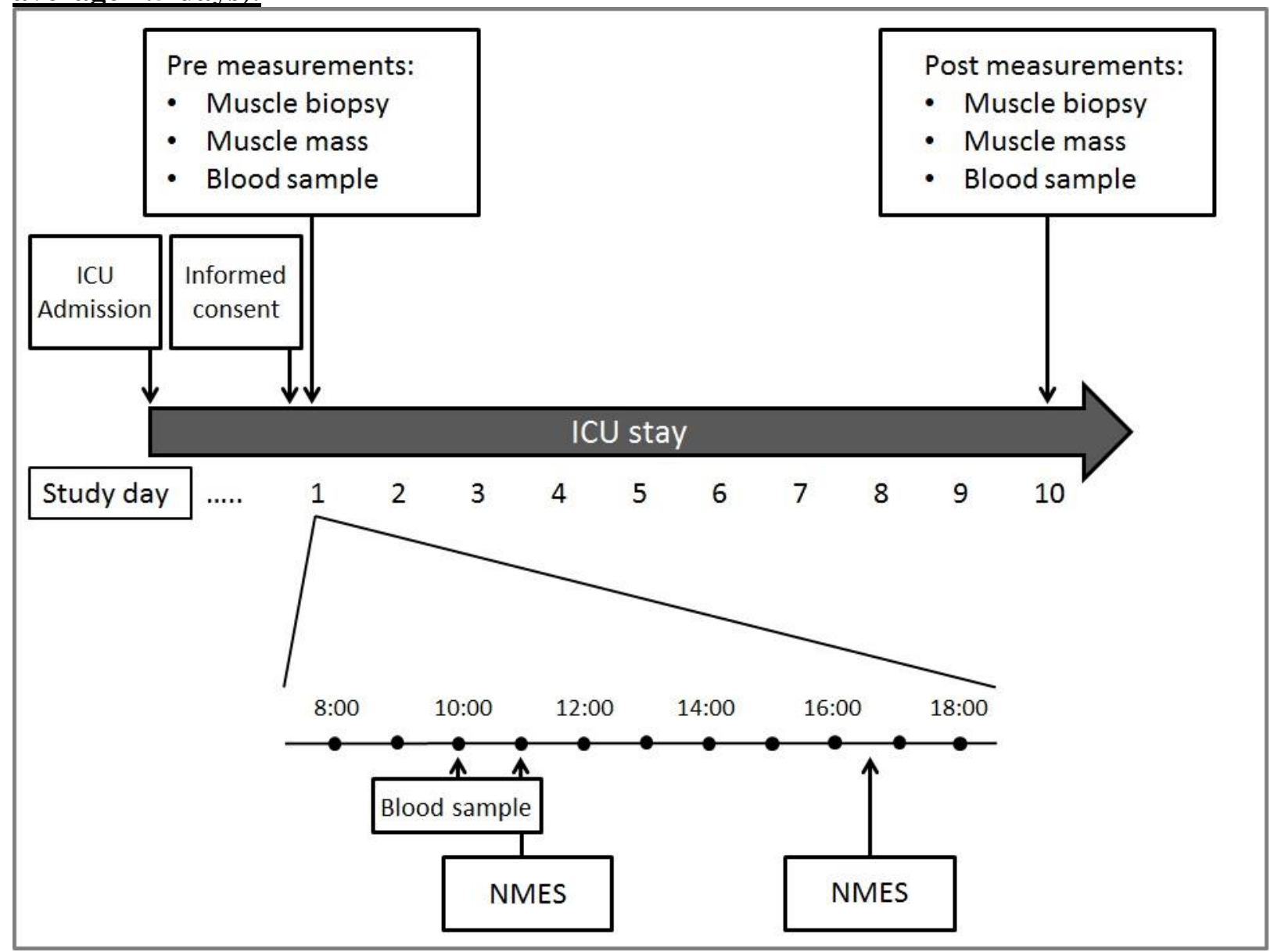

\section{Leg circumference measurements}

In the morning of day 1, circumference of the legs was measured using a tape measure at 5, 10 and $20 \mathrm{~cm}$ proximal to the top of the patella. The positions of leg circumference measurements were marked with semi-permanent ink to ensure the exact same measuring position during the post-measurements.

\section{Muscle analysis}

The part of the muscle sample that was mounted and frozen in Tissue-Tek (Sakura Finetek, Zoeterwoude, the Netherlands) was cut into $5 \mu \mathrm{m}$ thick cryosections using a cryostat at $-20^{\circ} \mathrm{C}$. Pre- and post-intervention samples of the NMES and CON leg of each subject were mounted together on uncoated, pre-cleaned glass slides, while care was taken to properly align the samples for cross-sectional fiber analyses. Staining were performed to measure muscle fiber typing (FT) and satellite cell (SC) content. To do this, slides were incubated with primary 


\section{Supplemental material}

antibodies directed against myosin heavy chain (MHC)-I (A4.840, dilution 1:25; Developmental Studies Hybridoma Bank, Iowa City, IA), laminin (polyclonal rabbit anti-laminin, dilution 1:50; Sigma, Zwijndrecht, the Netherlands) and Pax7 (neat; cell supernatant from cells obtained from the Developmental Studies Hybridoma Bank, Iowa City, IA, USA). Pax7 has been extensively used in the determination of SC content in human skeletal muscle by us [1] and others [2]. After washing, the appropriate secondary antibodies were applied: goat anti-rabbit IgG AlexaFluor647, goat anti-mouse IgM AlexaFluor555, and Streptavidin Alexa 488 (dilution 1:400, 1:500, and 1:200, respectively; Molecular Probes, Invitrogen, Breda, the Netherlands). Myonuclei were stained with 4,6-diamidino-2-phenylindole (DAPI, $0.238 \mu \mathrm{M}$; Molecular Probes). Both primary and secondary antibodies were diluted in 0.1\% Bovine Serum Albumin (BSA) in 0.1\% Tweenphosphate-buffered saline (PBS). All incubation steps were performed at room temperature. Staining of the muscle tissue was done as follows. After fixation in acetone for 5 min, slides were air dried and incubated with 3\% BSA in $0.1 \%$ Tween-PBS for 30 min. Slides were washed in PBS for $5 \mathrm{~min}$, and incubated with Pax7 for $2 \mathrm{~h}$. Thereafter, slides were washed (standard washing protocol: $5 \mathrm{~min} 0.1 \%$ Tween-PBS, $2 \times 5$ min PBS) and incubated with goat anti-mouse Biotin (dilution 1:133, Vector Laboratories, Inc., Burlingame, CA, USA) for $60 \mathrm{~min}$, washed again, and incubated with Streptavidin for $60 \mathrm{~min}$. After washing, primary antibodies against laminin and MHC-I were applied for $45 \mathrm{~min}$. Slides were then washed and incubated with the appropriate secondary antibodies, diluted together with DAPI. After a last washing step, slides were mounted with cover glasses Mowiol (Calbiochem, Amsterdam, the Netherlands). Staining procedures resulted in images with nuclei stained in blue, Pax7 in green, MHC-I in red, and laminin in far-red. Images were visualized and automatically captured at 10x magnification with a fluorescent microscope equipped with an automatic stage (IX81 motorized inverted microscope, Olympus, Hamburg, Germany) and EXi Aqua CCD camera (QImaging, Surrey, BC, Canada). Image acquisition was done by Micromanager 1.4 software [3], and images were analyzed with Image J software package (version 1.46r, National Institute of Health [4]). Recording and analyzing of the images was done by an investigator blinded to subject coding. As a measure of fiber circularity, form factors were calculated by using the following formula: $(4 \pi \cdot \mathrm{CSA}) /(\text { perimeter })^{2}$. No differences in fiber circularity were observed between legs or between pre- and post-intervention samples. Mean numbers of $257 \pm 33$ and $238 \pm 23$ muscle fibers were analyzed in the pre- and post-intervention samples, respectively.

The part of the muscle sample that was frozen in liquid nitrogen was used to determine mRNA and protein expression of several genes of interest. Frozen muscle $(10-20 \mathrm{mg})$ was used for mRNA isolation using Tri Reagent (Sigma-Aldrich, St. Louis, MO, USA), according to the manufacturer's protocol. Quantification of total RNA was carried out spectrophotometrically at $260 \mathrm{~nm}$ using the NanoDrop ND-1000 Spectrophotometer (Thermo Fisher Scientific, Madison, WI, USA), and RNA purity was determined as the ratio of readings at $260 / 280 \mathrm{~nm}$. Thereafter, first strand cDNA was synthesized from $1 \mu \mathrm{g}$ RNA sample using random primers (Promega, Madison, WI, USA) and PowerScript Reverse Transcriptase (Applied Biosystems, Foster City, CA, USA). Taqman PCR was carried out using an ABI Prism 7000 sequence detector (Applied Biosystems, USA), with $2 \mu \mathrm{L}$ of cDNA, $18 \mu \mathrm{l} \cdot \mathrm{L}^{-1}$ of each primer, $5 \mu \mathrm{l} \cdot \mathrm{L}^{-1}$ probe, and Universal Taqman $2 \times$ PCR mastermix (Eurogentec S.A., Seraing, Belgium) in a $25 \mu \mathrm{L}$ final volume. Each sample was run in duplicate, in duplex reactions. A separate standard curve was included for each gene, with serial dilutions of cDNA synthesized in parallel with the study samples. $18 \mathrm{~S}$ was selected as a housekeeping gene to be used as an internal control, as we have used it previously and have shown that it does not change with muscle disuse [5, 6], ENREF 14 ENREF 42 ENREF 15 


\section{Supplemental material}

i.e. mean $\mathrm{C} t$ values did not change over time in either leg (data not shown). Taqman primer/probe sets (Applied Biosystems) were obtained for the following genes of interest: mammalian target of rapamycin (mTOR), P70S6 kinase (P70S6K), myogenic factor 4 (myogenin), MyoD, myostatin, Atrogin-1/Muscle Atrophy F-box (MAFbx), Muscle RINGfinger protein-1 (MuRF1), Forkhead box protein O1 (FOXO1), Focal Adhesion Kinase (FAK), large neutral amino acid transporter (LAT1) and Proton-coupled amino acid transporter 1 (PAT1). All genes of interest were labeled with the fluorescent reporter FAM. Thermal cycling was performed using the following conditions: $2 \mathrm{~min}$ at $50^{\circ} \mathrm{C}, 10 \mathrm{~min}$ at $95^{\circ} \mathrm{C}$, followed by 40 cycles at $95^{\circ} \mathrm{C}$ for $15 \mathrm{~s}$ and $60^{\circ} \mathrm{C}$ for $1 \mathrm{~min}$. $\mathrm{C} t$ values of the genes of interest were normalized to $\mathrm{C} t$ values of $18 \mathrm{~S}$, and these values were calculated as relative expression against the standard curve. Muscle samples from age- and sex-matched healthy controls were analyzed to compare pre-intervention values of the patients in the study to healthy volunteers.

Muscle homogenates for Western blotting analysis were made using $40 \mathrm{mg}$ of muscle tissue in 7x volumes Tris buffer ( $20 \mathrm{mM}$ Tris-HCL, $5 \mathrm{mM}$ EDTA. $10 \mathrm{mM}$ Na-pyrosphospate, $100 \mathrm{mM}$ $\mathrm{NaF}, 2 \mathrm{mM}$ Na3VO4, $1 \%$ Nonident P-40; $\mathrm{pH}$ 7.4) supplemented with the following protease and phosphatase inhibitors: Aprotinin $10 \mu \mathrm{g} / \mathrm{mL}$, Leupeptin $10 \mu \mathrm{g} / \mathrm{mL}$, Benzamidin $3 \mathrm{mM}$ and PMSF $1 \mathrm{mM}$. Muscle samples were centrifuged for $10 \mathrm{~min}$ at $10,000 \mathrm{~g}\left(4^{\circ} \mathrm{C}\right)$, where after sample buffer (final concentration: $60 \mathrm{mM}$ Tris, $5 \%$ glycerol, $20 \mathrm{mg} / \mathrm{mL}$ SDS, $0.1 \mathrm{mM}$ DTT, $20 \mu \mathrm{g} / \mathrm{mL}$ bromophenolblue) was added to the supernatant. The solution was then boiled for $5 \mathrm{~min}$ at $100^{\circ} \mathrm{C}$, after which the samples were put on ice. Directly before the commencement of the analyses, the extraction sample was warmed to $50{ }^{\circ} \mathrm{C}$ and centrifuged for $1 \mathrm{~min}$ at $1,000 \mathrm{~g}$ at room temperature. Each lane on the gel was loaded with a total of $50 \mu \mathrm{g}$ muscle sample. Protein samples (for (p)Akt, (p)P70S6K and $\alpha$-actin quantification) were run on a Criterion 'any kD' gel (Biorad Order No. 567-1124) for $10 \mathrm{~min}$ at $50 \mathrm{~V}$ (constant voltage) and $\pm 90 \mathrm{~min}$ at $150 \mathrm{~V}$ (constant voltage) and transferred onto a Trans-blot Turbo $0.2 \mu \mathrm{m}$ nitrocellulose membrane (Biorad Order No. 170-4159) in $7 \mathrm{~min}$ at 2.5A and 25V. For (p)mTOR protein a Tris-acetate gel was used (Biorad Order nr. 345-0129), and the gel was transferred onto a Trans-blot Turbo 0.2 $\mu \mathrm{m}$ nitrocellulose membrane (Biorad Order No. 170-4159) in $10 \mathrm{~min}$ at 1.3A and 25V. Specific proteins were detected by overnight incubation at $4^{\circ} \mathrm{C}$ on a shaker with specific antibodies in $50 \%$ PBS/Odyssey blocking buffer (Li-Cor Biosciences Part No. 927-40000) after blocking for 60 min at RT in 50\% PBS/Odyssey blocking buffer. Antibodies that were used in this study were anti-Akt (60 kD; dilution 1:1000, \#9272 Cell Signaling) and anti-phospho-Akt (Ser473; $60 \mathrm{kD}$, dilution 1:1000, \#9271 Cell Signalling), anti-mTOR (289 kD; dilution 1:1000, \#2972 Cell Signalling) and anti-phospho-mTOR (Ser2448; 289 kD, dilution 1:1000, \#2971 Cell Signalling), anti-P70S6K (70 kD; dilution 1:1000, \#9202 Cell Signalling), anti-phospho P70S6K (Thr389; $70 \mathrm{kD}$, dilution 1:1000, \#9206 Cell Signalling) and anti $\alpha$-actin (42 kD; dilution 1:100.000, mouse monoclonal IgM, Sigma A2172). After incubation, membranes were washed 3 x 10 min in $0.1 \%$ PBS-Tween and $1 \times 10$ min with PBS. Samples were incubated for $1 \mathrm{~h}$ at room temperature with the following secondary antibodies: donkey anti-rabbit IRDYE 680 (Li-Cor, Cat. No. 926-32223, dilution 1:10000) and donkey anti-mouse IRDYE 800CW (Li-Cor, Cat. No. 926-32212, dilution 1:10000) dissolved in 50\% PBS Odyssey blocking buffer. After the last washing step ( $3 \times 5 \mathrm{~min}$ in $0.1 \%$ Tween 20 -PBS and $1 \times 10 \mathrm{~min}$ with PBS), protein quantification was performed by scanning on an Odyssey Infrared Imaging System (LI-COR Biotechnology, Lincoln, NE, USA). 
eResults

Laboratory results

eTable1: Average laboratory values during the study period

\begin{tabular}{lll}
\hline & Value & Reference value \\
\hline White blood cell count $(* \mathbf{1 0} / \mathbf{L})$ & $15.9 \pm 2.5$ & $4.5-11.0$ \\
Lymphocytes $(* \mathbf{1 0} / \mathbf{L})$ & $0.8 \pm 0.1$ & $1.01-3.38$ \\
Monocytes $(* \mathbf{1 0} / \mathbf{L})$ & $0.90 \pm 0.30$ & $<0.82$ \\
CRP $(\mathbf{m g} / \mathbf{d L})$ & $9.1 \pm 2.3$ & $<0.5$ \\
Ureum $(\mathbf{m g} / \mathbf{d L})$ & $74.6 \pm 10.9$ & $17-43$ \\
Creatinine $(\mathbf{m g} / \mathbf{d L})$ & $0.9 \pm 0.1$ & $0.51-0.95$ \\
Total plasma protein $(\mathbf{g} / \mathbf{d L})$ & $5.7 \pm 0.2$ & $6.6-8.3$ \\
Albumin $(\mathbf{g} / \mathbf{d L})$ & $2.8 \pm 0.1$ & $3.5-5.2$ \\
\hline
\end{tabular}

$\mathrm{CRP}=\mathrm{C}$-reactive protein

\section{Plasma amino acid concentrations}

Plasma concentrations of the measured amino acids are displayed in eTable2. Following the intervention, significant decreases in the concentrations of alanine, histidine and phenylalanine were observed (all $P<0.05)$, whereas for leucine a trend for a decline was seen $(P=0.065)$. 
eTable 2: Plasma AA concentrations

\begin{tabular}{lll}
\hline & Pre & Post \\
\hline a-aminobutyric acid & $47 \pm 10$ & $29 \pm 4$ \\
Alanine & $369 \pm 50$ & $241 \pm 31 *$ \\
Arginine & $66 \pm 16$ & $47 \pm 8$ \\
Asparagine & $63 \pm 10$ & $44 \pm 5$ \\
Aspartic acid & $4 \pm 1$ & $6 \pm 2$ \\
Citrulline & $18 \pm 3$ & $23 \pm 4$ \\
Cysteine & $40 \pm 11$ & $48 \pm 9$ \\
Glutamic acid & $46 \pm 15$ & $73 \pm 20$ \\
Glutamine & $470 \pm 59$ & $430 \pm 70$ \\
Glycine & $263 \pm 67$ & $189 \pm 24$ \\
Histidine & $81 \pm 4$ & $55 \pm 6 *$ \\
Isoleucine & $77 \pm 6$ & $60 \pm 7$ \\
Leucine & $158 \pm 9$ & $111 \pm 14$ \\
Lysine & $218 \pm 38$ & $145 \pm 19$ \\
Methionine & $40 \pm 6$ & $28 \pm 5$ \\
Ornithine & $90 \pm 18$ & $78 \pm 11$ \\
Phenylalanine & $99 \pm 10$ & $71 \pm 8 *$ \\
Proline & $161 \pm 21$ & 15833 \\
Serine & $85 \pm 14$ & $69 \pm 9$ \\
Taurine & $42 \pm 12$ & $45 \pm 8$ \\
Threonine & $139 \pm 28$ & $91 \pm 16$ \\
Tryptophan & $34 \pm 7$ & $31 \pm 6$ \\
Tyrosine & $77 \pm 13$ & $61 \pm 8$ \\
Valine & $283 \pm 22$ & $222 \pm 24$ \\
\hline Data & & \\
\hline
\end{tabular}

Data are presented as means \pm SEM.* Significantly different from pre-value $(P<0.05)$.

All values are presented as $\mu \mathrm{mol} / \mathrm{L}$.

Leg circumference 


\section{Supplemental material}

No baseline differences in leg circumference between NMES and CON legs were observed, and no effect of time or treatment occurred (both interaction and time effect $P>0.05$ ).

\section{mRNA analysis}

For myostatin (eFigure 3A), myoD (eFigure 3B), and myogenin (eFigure 3C), no differences were observed when compared with healthy controls and no interaction effect was found for the CON and NMES leg (all $P>0.05$ ). FAK (eFigure 3D) was higher in patients than in healthy controls $(P<0.05)$, but was not changed over time or between legs $(P>0.05)$. For both PGC-1 $\alpha$ (eFigure 3E) and citrate synthase (eFigure 3F) no differences between healthy controls and patients were observed (both $P<0.05)$. Although not significantly $(P>0.05)$, PGC- $1 \alpha$ tended to decrease over time in both legs. Citrate synthase showed a significant time*treatment interaction $(P<0.05)$; when both legs were tested separately with a paired-samples t-test a trend for a decline in the CON leg $(P=0.059)$ was observed, while in the NMES leg no decrease was observed $(P>0.05)$. The amino acid transporters LAT1 (eFigure 3G) and PAT1 (eFigure 3H) were not different (LAT1) or significantly higher (PAT1; $P<0.01$ ) in patients compared with healthy controls, whereas over time no changes were observed in either gene (both $P>0.05$ ). 
eFigure 3: Skeletal muscle mRNA expression of genes of interest in the CON and NMES leg of fully-sedated ICU patients (right part of the figure) versus healthy controls (left column), before (white bars) and after (black bars) $7 \pm 1$ days of twice-daily NMES. Abbreviations: FAK, Focal Adhesion Kinase; LAT1, Large Neutral Amino Acid Transporter 1; PAT1, Proton-coupled amino acid transporter 1; PGC-1 $\alpha$, Peroxisome proliferator-activated receptor gamma coactivator 1-alpha. * Significantly different from the mean pre-intervention value of the CON and NMES legs. \# Significant interaction effect $(P<0.05)$.
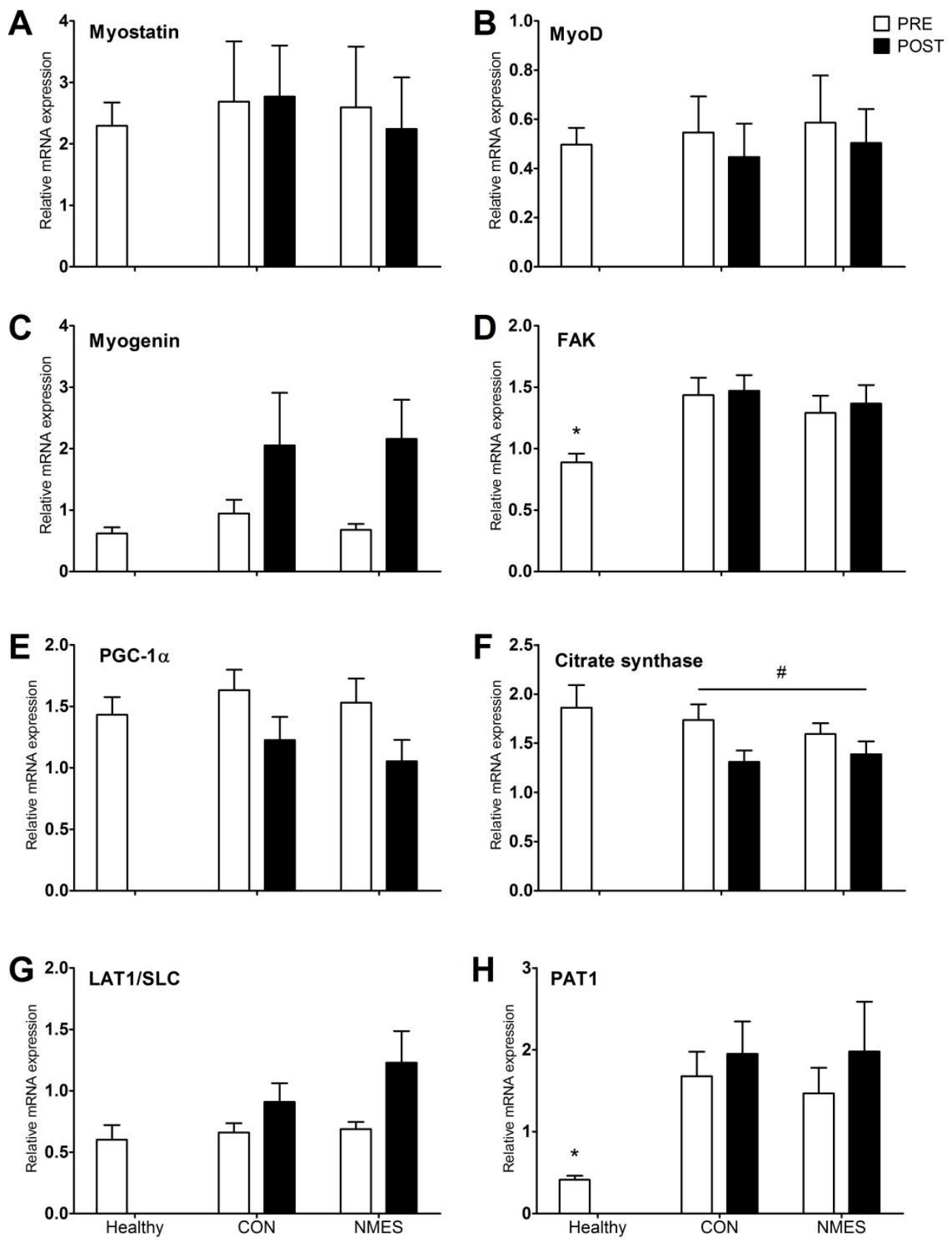


\section{Supplemental material}

\section{Supplemental References}

1 Verdijk LB, Koopman R, Schaart G, Meijer K, Savelberg HH, van Loon L. Satellite cell content is specifically reduced in type II skeletal muscle fibers in the elderly. Am J Physiol Endocrinol Metab 2007; 292: E151-7.

2 Mackey AL, Andersen LL, Frandsen U, Suetta C, Sjogaard G. Distribution of myogenic progenitor cells and myonuclei is altered in women with vs. those without chronically painful trapezius muscle. $J$ Appl Physiol 2010; 109: 1920-9.

3 Edelstein A, Amodaj N, Hoover K, Vale R, Stuurman N. Computer control of microscopes using $\mu$ Manager. Curr Protoc Mol Biol 2010; Chapter 14.

$4 \quad$ Strandberg S, Wretling ML, Wredmark T, Shalabi A. Reliability of computed tomography measurements in assessment of thigh muscle cross-sectional area and attenuation. BMC Med Imaging 2010; 10: 18.

5 Wall BT, Snijders T, Senden JM, Ottenbros CL, Gijsen AP, Verdijk LB, van Loon LJ. Disuse impairs the muscle protein synthetic response to protein ingestion in healthy men. $J$ Clin Endocrinol Metab 2013; 98: 4872-81.

6 Dirks ML, Wall BT, Snijders T, Ottenbros CL, Verdijk LB, van Loon LJ. Neuromuscular electrical stimulation prevents muscle disuse atrophy during leg immobilization in humans. Acta Physiol (Oxf) 2014; 210: 628-41. 